\title{
TOTAL DOMINATION IN GENERALIZED PRISMS AND A NEW DOMINATION INVARIANT
}

\author{
Aleksandra TePeh \\ FEECS, University of Maribor \\ Koroška cesta 46, 2000 Maribor, Slovenia \\ Faculty of Information Studies \\ Ljubljanska cesta 31a, 8000 Novo Mesto, Slovenia \\ e-mail: aleksandra.tepeh@um.si
}

\begin{abstract}
In this paper we complement recent studies on the total domination of prisms by considering generalized prisms, i.e., Cartesian products of an arbitrary graph and a complete graph. By introducing a new domination invariant on a graph $G$, called the $k$-rainbow total domination number and denoted by $\gamma_{k \mathrm{rt}}(G)$, it is shown that the problem of finding the total domination number of a generalized prism $G \square K_{k}$ is equivalent to an optimization problem of assigning subsets of $\{1,2, \ldots, k\}$ to vertices of $G$. Various properties of the new domination invariant are presented, including, inter alia, that $\gamma_{k \mathrm{rt}}(G)=n$ for a nontrivial graph $G$ of order $n$ as soon as $k \geq 2 \Delta(G)$. To prove the mentioned result as well as the closed formulas for the $k$ rainbow total domination number of paths and cycles for every $k$, a new weight-redistribution method is introduced, which serves as an efficient tool for establishing a lower bound for a domination invariant.
\end{abstract}

Keywords: domination, $k$-rainbow total domination, total domination.

2010 Mathematics Subject Classification: 05C69, 05C76.

\section{REFERENCES}

[1] H.A. Ahangar, J. Amjadi, N. Jafari Rad and V. Samodivkin, Total k-Rainbow domination numbers in graphs, Commun. Comb. Optim. 3 (2018) 37-50. https://doi.org/10.22049/CCO.2018.25719.1021

[2] J. Amjadi, N. Dehgardi, M. Furuya and S.M. Sheikholeslami, A sufficient condition for large rainbow domination number, Int. J. Comput. Math. Comput. Sys. Theory 2 (2017) 53-65.

https://doi.org/10.1080/23799927.2017.1330282 
[3] J. Azarija, M.A. Henning and S. Klavžar, (Total) domination in prisms, Electron. J. Combin. 24 (2017) \#P1.19. https://doi.org/10.327236/6288

[4] B. Brešar, T.R. Hartinger, T. Kos and M. Milanič, On total domination in the Cartesian product of graphs, Discuss. Math. Graph Theory 38 (2018) 963-976. https://doi.org/10.7151/dmgt.2039

[5] B. Brešar, Vizing's conjecture for graphs with domination number 3 - a new proof, Electron. J. Combin. 22 (2015) \#P3.38. https://doi.org/10.37236/5182

[6] B. Brešar, Improving the Clark-Suen bound on the domination number of the Cartesian product of graphs, Discrete Math. 340 (2017) 2398-2401. https://doi.org/10.1016/j.disc.2017.05.007

[7] B. Brešar, P. Dorbec, W. Goddard, B.L. Hartnell, M.A. Henning, S. Klavžar and D.F. Rall, Vizing's conjecture: A survey and recent results, J. Graph Theory 69 (2012) 46-76. https://doi.org/10.1002/jgt.20565

[8] B. Brešar, M.A. Henning and D.F. Rall, Rainbow domination in graphs, Taiwanese J. Math. 12 (2008) 213-225. https://doi.org/10.11650/twjm/1500602498

[9] B. Brešar and T.K. Šumenjak, On the 2-rainbow domination in graphs, Discrete Appl. Math. 155 (2007) 2394-2400. https://doi.org/10.1016/j.dam.2007.07.018

[10] S. Brezovnik and T.K. Šumenjak, Complexity of k-rainbow independent domination and some results on the lexicographic product of graphs, Appl. Math. Comput. 349 (2019) 214-220. https://doi.org/10.1016/j.amc.2018.12.009

[11] K. Choudhary, S. Margulies and I.V. Hicks, A note on total and paired domination of Cartesian product graphs, Electron. J. Combin. 20 (2013) \#P25. https://doi.org/10.37236/2535

[12] W. Desormeaux and M.A. Henning, Paired domination in graphs: A survey and recent results, Util. Math. 94 (2014) 101-166.

[13] W. Goddard and M.A. Henning, A note on domination and total domination in prisms, J. Comb. Optim. 35 (2018) 14-20. https://doi.org/10.1007/s10878-017-0150-0

[14] M.A. Henning and D.F. Rall, On the total domination number of Cartesian products of graphs, Graphs Combin. 21 (2005) 63-69. https://doi.org/10.1007/s00373-004-0586-8

[15] M.A. Henning and A. Yeo, Total Domination in Graphs (Springer, New York, 2013). https://doi.org/10.1007/978-1-4614-6525-6

[16] P.T. Ho, A note on the total domination number, Util. Math. 77 (2008) 97-100. 
[17] P. Kumbargoudra and J.V. Kureethara, Total k-rainbow domination in graphs, Int. J. Civ. Eng. Technol. 8 (2017) 867-875.

[18] Y. Lu and X. Hou, Total domination in the Cartesian product of a graph and $K_{2}$ or $C_{n}$, Util. Math. 83 (2010) 313-322.

[19] Z. Shao, S.M. Sheikholeslamib, B. Wang, P. Wu and X. Zhang, Trees with equal total domination and 2-rainbow domination numbers, Filomat 32 (2018) 599-607. https://doi.org/10.2298/FIL1802599S

[20] T.K. Šumenjak, D.F. Rall and A. Tepeh, On k-rainbow independent domination in graphs, Appl. Math. Comput. 333 (2018) 353-361. https://doi.org/10.1016/j.amc.2018.03.113

Received 14 June 2019

Revised 12 September 2019

Accepted 18 September 2019 